\title{
SEPARAÇÃO DE PROTEÍNAS DE UMA SOLUÇÃO SALINA POR MEMBRANA DE DIÁLISE DE ACETATO DE CELULOSE
}

\section{PROTEINS SEPARATION FROM A SALINE SOLUTION BY MEANS OF CELLULOSE ACETATE DIALYSIS MEMBRANE}

\author{
D. C. A. ABREU1', K. C. de S. FIGUEIREDO' ${ }^{1}$ \\ ${ }^{1}$ Universidade Federal de Minas Gerais, Escola de Engenharia, Departamento de Engenharia \\ Química, Brasil \\ E-mail: danielly.abreu@yahoo.com.br
}

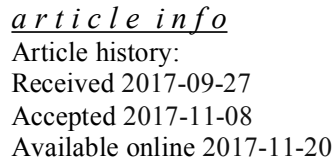
PALAVRAS-CHAVE: Diálise; Separação; Membrana polimérica; Proteína; Ensino.
KEYWORDS: Dialysis; Separation; Polymeric Membrane; Protein; Teaching.

RESUMO: Processos de separação por membranas são de grande interesse na separação de macromoléculas, como as proteinas. Nesses processos, ocorre a passagem de uma suspensão através da membrana, ocorrendo separação seletiva dos componentes sob o efeito de uma força motriz. No caso da diálise, essa força motriz é um gradiente de concentração das espécies através da membrana e o fluxo é de natureza difusiva. A diálise tem inúmeras aplicações na separação de componentes e esse trabalho apresenta um experimento didático, de fácil visualização desse fenômeno. Para tal, utilizou-se uma membrana comercial polimérica de acetato de celulose para separar proteínas de uma solução de leite em pó contendo cloreto de sódio. O monitoramento da concentração de sal e de proteina na solução dialisante foi feito ao longo do tempo para avaliar a transferência de massa através da membrana. A rejeição da membrana à proteína foi de 99,8\%, enquanto a concentração salina foi reduzida em 81 vezes.

ABSTRACT: Membrane separation processes are of great interest in the separation of macromolecules, such as proteins. In these processes, the transport of a suspension occurs through the membrane occurring selective separation of the components under the effect of a driving force. In the case of dialysis, the driving force is a concentration gradient of the species across the membrane and the flow has a diffusive nature. Dialysis has numerous applications in the separation of components and this work presents a didactic experiment of easy visualization of this phenomenon. For this purpose, a commercial cellulose acetate polymeric membrane was used to separate proteins from a powdered milk solution containing sodium chloride. Monitoring of the salt and protein concentration in the dialysate solution was done over time to evaluate the mass transfer through the membrane. The rejection of the membrane to the protein was $99.8 \%$, with saline concentration decreased in 81 times.

\section{INTRODUÇÃO}

Membranas são de grande interesse na separação de macromoléculas, como as proteínas, pelo fato de serem processos com baixo consumo energético e sem mudança de 
fase (SALGIN et al., 2006). Em particular, a diálise, em comparação com alguns processos convencionais, demostra significante superioridade: maior eficiência na purificação de águas residuais, melhoria da qualidade de produtos, baixo consumo de energia (ocorre sob pressão atmosférica), baixo custo de instalação e operação e não acarreta poluição ao meio ambiente (LUO et al., 2011).

Em um processo de separação por membranas, há o transporte de uma suspensão ou solução através de uma barreira semipermeável, ocorrendo a separação seletiva dos componentes, sob o efeito de uma força motriz adequada (ARMOA e JAFELICCI, 2011).

No caso da diálise, essa força motriz é devido a uma diferença de potencial químico entre o retido e o dialisado. Sendo o retido e o dialisado compostos pelo mesmo solvente, diferindo ligeiramente em concentração, pode-se assumir que as concentrações de solutos são proporcionais às atividades e, então, o gradiente de concentração pode ser usado para descrever satisfatoriamente essa força motriz (YEH e HSU, 2013). Além disso, o fluxo através da membrana é de natureza difusiva: as espécies se difundem, no meio em que se encontram, através dos poros da membrana, inchados pelo solvente (HABERT et al., 2006). Esse transporte acontece porque os poros da membrana são muito pequenos, o que favorece o movimento das moléculas menores enquanto as macromoléculas têm coeficientes de difusão muito mais baixos (MULDER, 1996).

Dois parâmetros importantes na diálise são a massa molar de corte (MWCO) e o fluxo. O primeiro é governado pelo tamanho dos poros (CASTRO et al., 2008) e é definido como sendo o valor da massa molar para a qual a membrana apresenta um coeficiente de rejeição de 95\% (HABERT et al., 2006). O segundo, utilizado para a avaliação do desempenho das membranas, é o volume que atravessa a membrana por área e tempo.

As membranas de diálise são hidrofílicas, nanoporosas, homogêneas ou de troca iônica. O desenvolvimento da tecnologia de separação por diálise veio ganhando importância rapidamente, principalmente para o tratamento da insuficiência renal e pode ser considerada uma indústria de milhões de dólares (IDRIS e YET, 2006). Grande atenção tem sido dada à biocompatibilidade dessas membranas, pois, nesse caso, o uso de membranas de baixa compatibilidade pode ocasionar o fenômeno de coagulação devido à ocorrência de adsorção de proteína, o que potencialmente inibe o combate a infecções, resultando em pior evolução e maior mortalidade em pacientes hemodialisados (SANTOS, 2014).

Além da hemodiálise, algumas aplicações conhecidas e estudadas para a diálise são: isolamento de analitos de amostras complexas (CASTRO el al., 2008), purificação de proteínas (MORAES et al., 2013), recuperação de ácidos e álcalis das descargas da produção de aço, nesse caso por meio de membranas de diálise de troca iônica (LUO et al., 2011; LIN et al., 2016) e recuperação de cloreto e acetato de sódio com membranas de diálise modificadas (XU et al., 2017). Existe uma grande preocupação com relação à geração de sais como resíduos nos diversos processos, como nas indústrias bioquímica, de alimentos e medicamentos. A descarga direta desses licores salinos não só desperdiça recursos úteis como também polui os rios. Geralmente, o que se utiliza para o tratamento dessas soluções é a cristalização, osmose inversa ou nanofiltração, que são de alto consumo de energia. A diálise, por outro lado, utiliza a diferença de concentração como força motriz e, por isso, tem 
vantagens de baixo consumo de energia, além de baixo custo de instalação e de operação (XU, 2017).

No entanto, a diálise tem como limitação a capacidade de processamento e consequentemente, é considerada menos importante do que outros processos de separação por membranas, mas devido às suas vantagens únicas como benignidade ambiental e baixo consumo de energia, pode se tornar mais competitiva à medida que a poluição ambiental e a escassez de energia se tornam mais graves (LUO et al., 2011).

O objetivo desse trabalho é apresentar um experimento simples e didático, no qual é possível avaliar o comportamento de uma membrana de diálise na separação de proteínas de uma solução salina e quantificar a transferência de massa por difusão através dessa membrana ao longo do tempo.

\subsection{Membranas de Celulose}

As membranas de celulose são constituídas pelo monômero de celobiose, conforme observado na Figura 1. Esse dissacarídeo tem estrutura de anel e é ricamente dotado de grupos hidroxilas (NUNES, 2011).

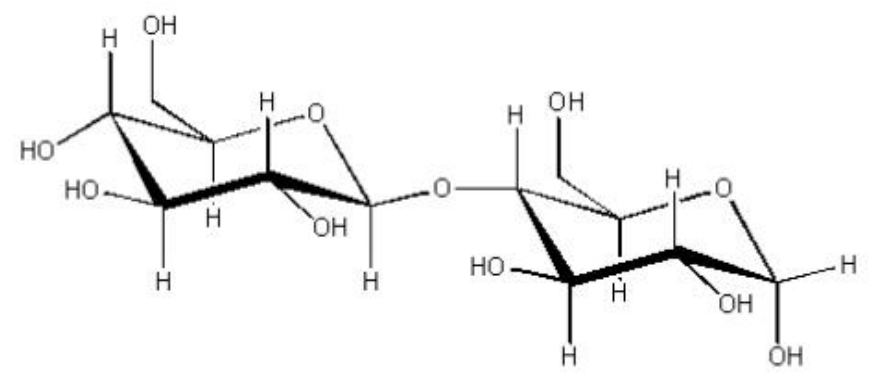

Figura 1- Estrutura da celobiose presente na membrana de celulose (NUNES, 2011).

Entre os materiais poliméricos, o acetato de celulose tem sido usado para o preparo de membranas de diálise devido à permeabilidade, seletividade e propriedades físicas ótimas como resistência e flexibilidade. Além disso, os polímeros de acetato de celulose se destacam devido a características como boa tenacidade, biocompatibilidade, alto fluxo e custo relativamente baixo (IDRIS e YET, 2006).

\section{EXPERIMENTAL}

\subsection{Materiais}

Utilizou-se uma membrana de diálise polimérica comercial de acetato de celulose, fornecida pela Sigma-Aldrich, com diâmetro médio de $21 \mathrm{~mm}$, MWCO de $14 \mathrm{kDa}$, cortada em amostras de aproximadamente $10 \mathrm{~cm}$ de comprimento. Albumina de soro bovino, BSA, com pureza maior ou igual a $98 \%$ em massa e solução de Bradford, ambas fornecidas pela SigmaAldrich, assim como espectrofotômetro na região do visível, marca/modelo CELM E-225D, foram usados para a quantificação do teor de proteína. Outras soluções utilizadas foram solução 
tampão de fosfato de potássio $0,1 \mathrm{M} \mathrm{pH} \mathrm{7,0;} \mathrm{solução} \mathrm{de} \mathrm{cloreto} \mathrm{de} \mathrm{sódio} 4 \mathrm{M}$ e $0,005 \mathrm{M}$ e solução de nitrato de prata $0,01 \mathrm{M}$.

Para representar a proteína nesse sistema, escolheu-se como moléculas-modelo as proteínas presentes no leite em pó. As proteínas do leite são veículos naturais que fornecem micronutrientes essenciais e estão distribuídas em duas grandes classes, $80 \%$ de caseína e $20 \%$ de proteínas do soro. A caseína, proteína mais representativa do leite, consite de 4 proteínas principais: $\alpha_{\mathrm{s} 1}, \alpha_{\mathrm{s} 2}, \beta$ e $\kappa$-caseína com massas moleculares de 23, 25, 24 e $19 \mathrm{kDa}$, respectivamente (BRASIL, 2013). Considerando isso, a membrana escolhida para a separação foi uma membrana polimérica de acetato de celulose com MWCO de $14 \mathrm{kDa}$. Para representar o sal e simular processos de diluição de resíduos salinos, escolheu-se como molécula-modelo o cloreto de sódio. A motivação aqui também foi simular uma situação muito comum na indústria que ocorre no processo de salting-out. Esse processo de separação de proteínas se baseia na precipitação da proteína em solução com altas concentrações de sais. O sal é utilizado para diminuir a interação entre a água e os grupos polares da proteína, diminuindo a sua solubilidade e fazendo com que essa seja precipitada (TRINDADE, 2014). Isso significa, portanto, que um processo posterior deve ser feito para separação das proteínas da solução salina e esse processo está aqui representado pela diálise. Além disso, tendo em vista que a proposta é uma prática para graduação, buscou-se trabalhar com materiais/ reagentes conhecidos e de fácil acesso.

Para a padronização, o cloreto de sódio, padrão primário, pureza maior que $99 \%$ em massa, marca Synth, foi seco a $150^{\circ} \mathrm{C}$, por $1 \mathrm{~h}$.

Leite em pó Itambé® comercial foi utilizado para o preparo da solução proteica $(1 \% \mathrm{~m} / \mathrm{v}$ de leite em pó) e solução de cromato de potássio $5 \%$ em massa, preparada com cromato de potássio PA Vetec, com pureza mínima de $99 \%$ em massa, foi utilizada como indicador para a titulação dos íons cloreto.

Para a montagem do sistema, utilizou-se ainda, presilhas para fechar a membrana e agitador magnético Biobase SH-3 para manter o sistema sob agitação. A variação da condutividade com o tempo foi avaliada por meio do condutivímetro MCA 150.

\subsection{Métodos}

Preparo da membrana: A membrana foi previamente lavada em água corrente por 2 minutos e, em seguida, foi deixada em repouso mergulhada em água destilada por $2 \mathrm{~h}$ para a remoção da glicerina contida nos poros da matriz polimérica.

Construção da curva de calibração para a proteína: $50 \mathrm{~mL}$ de solução 0,1 g.L $\mathrm{L}^{-1}$ de BSA foi preparada dissolvendo-se $0,005 \mathrm{~g}$ da proteína em solução tampão de fosfato $0,1 \mathrm{M}, \mathrm{pH} 7,0$. Para o preparo dos padrões, os seguintes volumes foram pipetados desta solução e diluídos para $10 \mathrm{~mL}$ de água destilada: $0,2,4,8$ e $10 \mathrm{~mL}$, obtendo-se as seguintes concentrações finais: $0 ; 0,02 ; 0,04$; 0,06; 0,08 e $0,1 \mathrm{mg} \cdot \mathrm{mL}^{-1}$. Pipetou-se, então, $1,8 \mathrm{~mL}$ de cada um dos padrões preparados para tubos com tampa e adicionou-se a cada um deles $18 \mathrm{~mL}$ de reagente de Bradford. Agitou-se cada frasco, deixando-se em repouso, em seguida, por 10 min para ocorrer a reação. As leituras no espectrofotômetro foram realizadas em $600 \mathrm{~nm}$. 
Esse método de quantificação de proteínas, conhecido por método de Bradford, é um dos métodos com maior índice de citação na literatura e nesta técnica, o corante Coomassie Blue, presente no reagente de Bradford, forma um complexo com proteínas que contenham aminoácidos básicos e/ou aromáticos e a interação entre a proteína e o corante acarreta na alteração do comprimento de onda de absorção máxima do corante de $465 \mathrm{~nm}$ (corante livre) para $600 \mathrm{~nm}$ (corante complexado à proteína) (MORAES et al., 2013).

Montagem do sistema: Pipetaram-se $10,0 \mathrm{~mL}$ da solução de leite em pó e $1,0 \mathrm{~mL}$ da solução de cloreto de sódio $4 \mathrm{M}$ e transferiu-se para a membrana de diálise com uma das extremidades já hermeticamente fechada com presilha. A segunda extremidade também foi hermeticamente fechada com a outra presilha. Certificou-se que a membrana estava completamente fechada e o sistema foi transferido para um béquer com $1 \mathrm{~L}$ de água destilada e foi mantido sob agitação, como apresentado na Figura 2.

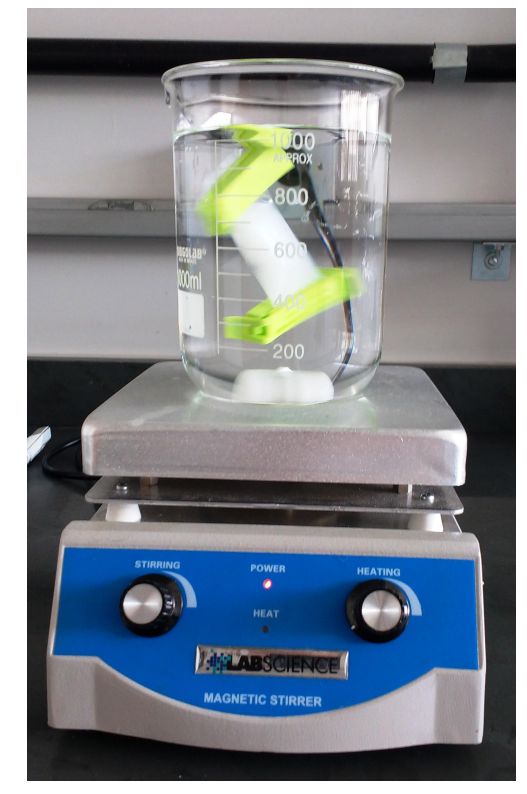

Figura 2- Sistema para separação de moléculas por diálise. A membrana de diálise contém a mistura de solução de leite em pó e solução salina.

Monitoramento da concentração de cloreto na solução dialisante: Alíquotas de 10,0 mL da solução dialisante foram retiradas em intervalos de 15 minutos para que a concentração de cloreto nessa solução fosse monitorada com o tempo. Coletaram-se $30,0 \mathrm{~mL}$ de uma só vez para que análise fosse realizada em triplicata. Para tal análise, foi utilizado o método de Mohr. Esse método se baseia em titular a amostra com uma solução de nitrato de prata padronizada na presença de um indicador, cromato de potássio, até que ocorra a precipitação do cromato de prata de cor marrom- avermelhado, quando todos os íons cloretos forem consumidos. Cada alíquota foi diluída para $50 \mathrm{~mL}$ em erlenmeyer e foram adicionadas 3 gotas de indicador. Além disso, foram realizadas medidas de condutividade na solução dialisante a cada 10 minutos.

Monitoramento da concentração de proteína na solução dialisante: $\mathrm{O}$ monitoramento da 
concentração de proteína da solução dialisante foi realizado baseado em medidas da absorbância em espectrofotômetro cujo preparo da curva de calibração foi descrito anteriormente. A cada 15 minutos, uma amostra de $1,8 \mathrm{~mL}$ da solução dialisante foi coletada e transferida para um frasco âmbar com tampa e a cada um deles foi adicionado $18 \mathrm{~mL}$ do regente de Bradford. As amostras foram agitadas e guardadas em geladeira para que as leituras no espectrofotômetro em $600 \mathrm{~nm}$ fossem realizadas posteriormente, mas dentro de um intervalo de tempo máximo de 1 hora.

\section{RESULTADOS E DISCUSSÃO}

A curva de calibração obtida para a quantificação da proteína é apresentada na Figura 3, enquanto o ajuste é mostrado na Equação 1, com coeficiente de correlação igual a 0,9766.

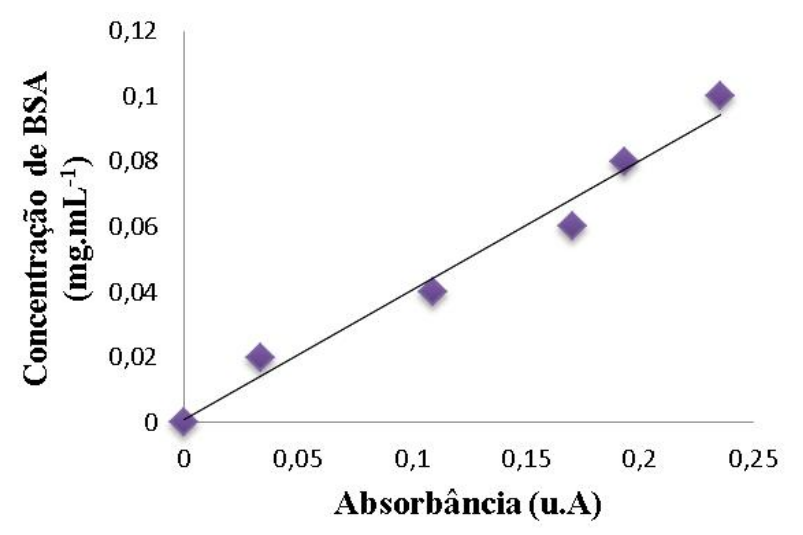

Figura 3- Curva de calibração para a quantificação de proteína.

$$
C=0,3976 A+0,0007
$$

Na Equação 1, A é a absorbância, em unidades de absorbância, e C é a concentração de proteína, em mg.mL $\mathrm{mL}^{-1}$.

A curva de calibração apresentou ajuste satisfatório e, portanto, pôde ser utilizada para verificar a concentração da proteína na solução dialisante ao longo do tempo. Por meio dessa calibração, do método titulométrico de precipitação descrito acima e pelas medidas de condutividade foi possível obter o gráfico da Figura 4 que apresenta as variações das concentrações de cloreto, da proteína e da condutividade ao longo do tempo de experimento. 


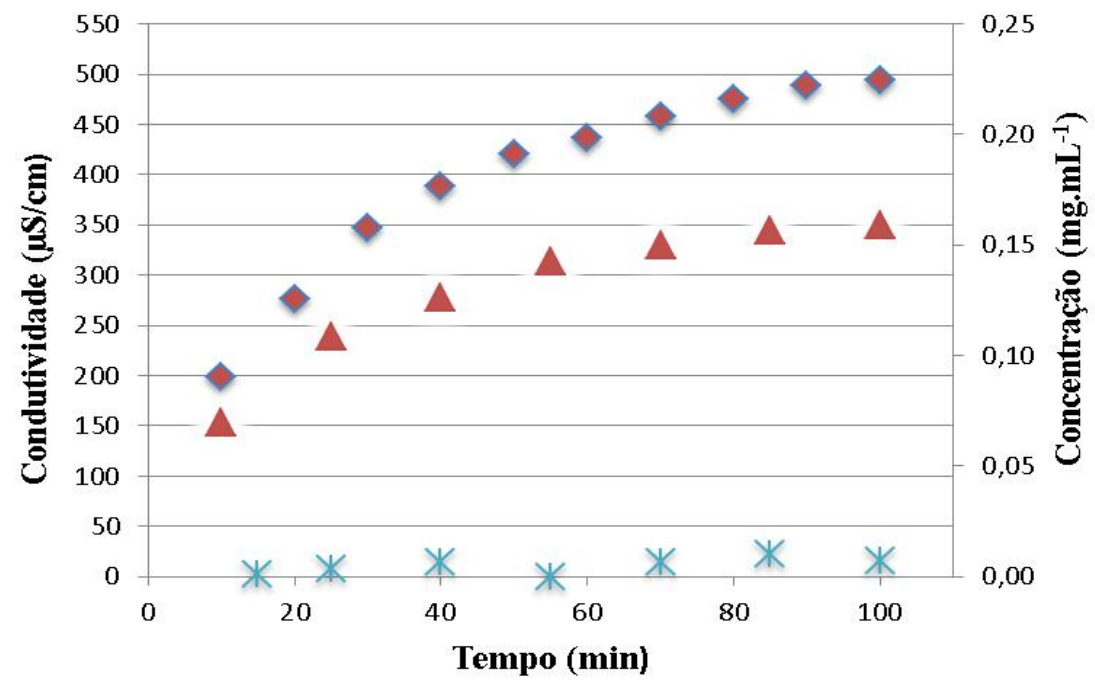

- Condutividade $*$ Concentração de proteína $\Delta$ Concentração de cloreto

Figura 4- Variação da concentração de cloreto, proteína e condutividade ao longo do tempo de experimento na solução dialisante.

Conforme é possível observar do gráfico da Figura 4, à medida que o tempo de experimento aumenta, a concentração de cloreto e a condutividade da solução dialisante também aumentam. Esse resultado é esperado, pois a membrana apresentando um MWCO de $14 \mathrm{kDa}$ permite que íons pequenos, como os de cloreto, atravessem a membrana. Além disso, os íons cloretos apresentam coeficientes de difusão maiores do que as proteínas devido o seu tamanho, o que justifica a maior mobilidade desses íons. A concentração final de cloreto, analisado no tempo de 100 minutos, foi de $0,0045 \mathrm{~mol}$. $\mathrm{L}^{-1}$, significando que houve uma diluição de 81 vezes da solução salina da alimentação.

A condutividade de uma solução é devida à parcela de sais dissolvidos e é aproximadamente proporcional à quantidade desses sais (HELLER e PÁDUA, 2006). Nesse experimento, a diferença de inclinação que existe entre a curva da concentração de cloreto e a curva da condutividade pode ser explicada pela presença de outros sais na solução de leite de pó, como cálcio e sódio, que podem ter contribuído com a condutividade total.

Verifica-se, também, que no início do experimento esse aumento ocorre de forma mais pronunciada e essa curva tende a atingir um equilíbrio para tempos maiores. Esse fato é justificado porque a difusão dessas partículas ocorre devido a um gradiente de concentração, maior no início do experimento. O fluxo dos sais ocorre da região de maior concentração (de dentro da membrana) para a de menor concentração (solução dialisante externa) até que se atinja o equilíbrio, de forma que essas moléculas que são capazes de atravessar a membrana se diluem por todo o recipiente (MORAES et al., 2013). No gráfico da Figura 4, é possível observar essa tendência para atingir o equilíbrio. 
De fato, o processo de separação ocorre de forma rápida. Em 100 minutos de experimento, já foi possível verificar a tendência à estabilização da concentração na solução dialisante, o que torna o experimento ideal para aplicação em práticas de laboratório.

Apresenta-se, na Figura 5, um esquema do perfil de concentração de cloreto através da membrana, em que as resistências de transporte do sal na membrana e no líquido dialisante são desprezados. A partir destas considerações, o coeficiente de transferência de massa pode ser estimado pela razão entre o fluxo e a diferença de concentração, conforme a Equação 2, em que $\mathrm{k}$ é o coeficiente de transferência de massa, $\mathrm{N}_{\mathrm{A}}$ é o fluxo molar, $\Delta \mathrm{C}$ é a diferença de concentração através da membrana, $\Delta \mathrm{n}$ é o número de moles de cloreto que atravessam a membrana no tempo, $\mathrm{t}$, de 100 minutos, e d e L são o diâmetro e o comprimento da membrana.

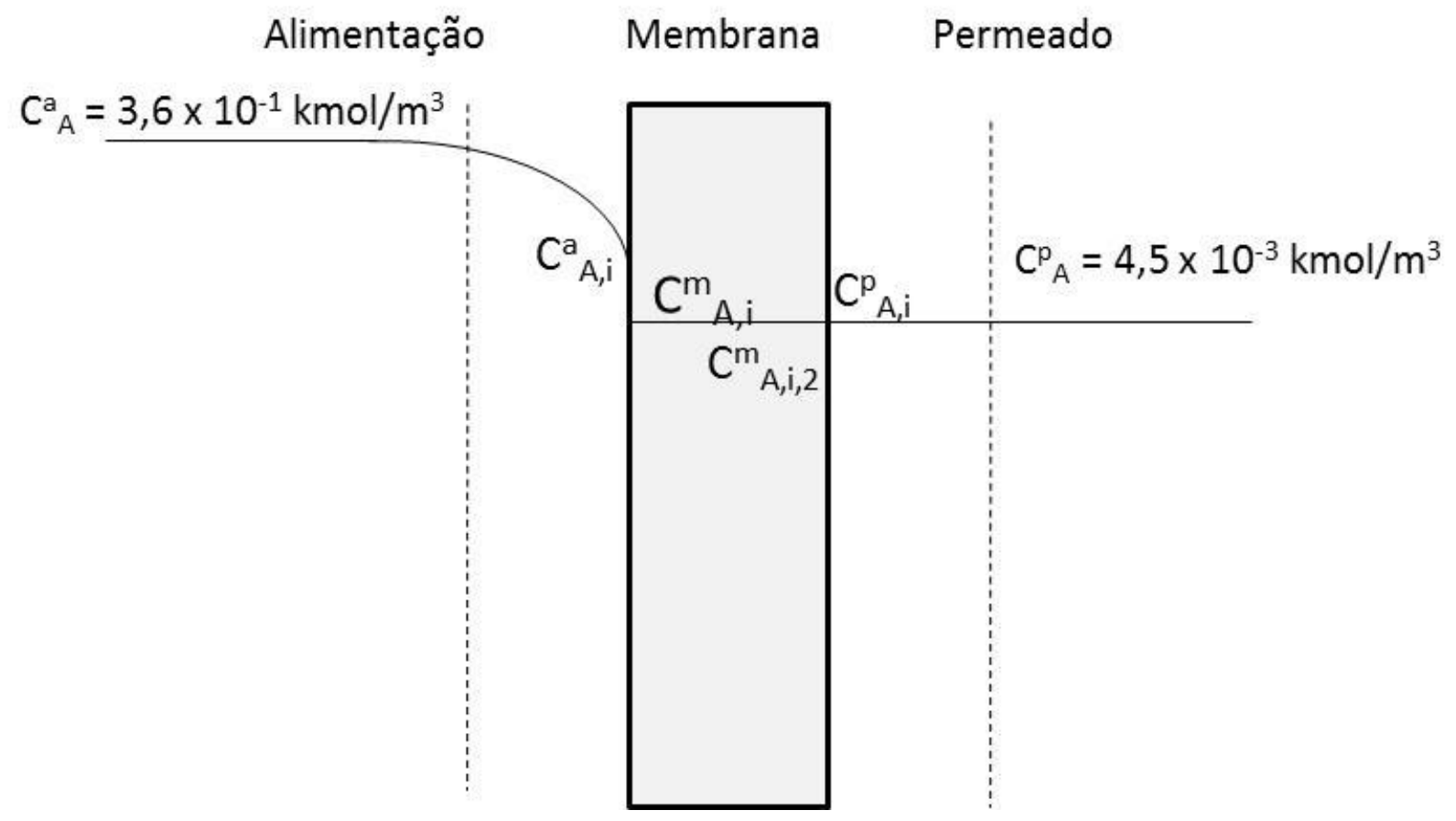

Figura 5- Esquema do perfil de concentração de cloreto nas interfaces da membrana com a alimentação e com a solução disalisante. $\mathrm{C}_{\mathrm{A}}^{\mathrm{a}}$ é a concentração do cloreto na alimentação, $\mathrm{C}_{\mathrm{A}, \mathrm{i}}^{\mathrm{a}}$ é a concentração de cloreto na alimentação junto à interface alimentação/membrana, $\mathrm{C}_{\mathrm{A}, \mathrm{i}}$ é a concentração de cloreto na membrana junto à interface alimentação/membrana, $\mathrm{C}^{\mathrm{m}}{ }_{\mathrm{A}, \mathrm{i}, 2}$ é a concentração de cloreto na membrana junto à interface membrana/permeado, $\mathrm{C}_{\mathrm{A}, \mathrm{i}}^{\mathrm{p}}$ é a concentração do cloreto no permeado, junto à interface membrana/permeado e $\mathrm{C}_{\mathrm{A}} \mathrm{e}$ é concentração de cloreto no permeado.

$k=N_{A} / \Delta C=\Delta n /(\pi d L \Delta t \Delta C)$

Assim, o coeficiente de transferência de massa foi estimado em $3,2 \times 10^{-11} \mathrm{~cm} / \mathrm{s}$.

A concentração de proteína na solução dialisante permanceu próxima de zero durante 
todo o período de experimento, atingindo uma concentração média de $0,0049 \mathrm{mg} \cdot \mathrm{mL}^{-1}$, e isso comprova que moléculas grandes como a proteína não se difudem pela membrana em quantidade apreciável. Esse resultado é justificado pelo fato das principais proteínas do leite $\left(\alpha_{\mathrm{s} 1}, \alpha_{\mathrm{s} 2}, \beta\right.$ e k-caseína) apresentarem massas moleculares maiores do que o MWCO da membrana que é $14 \mathrm{kDa}$. Essa concentração de $0,0049 \mathrm{mg} \cdot \mathrm{mL}^{-1}$ se refere a um valor médio de concentração de proteína em todas as amostras coletadas. Esse resultado demonstra o potencial da diálise para a separação e concentração de proteínas.

Por meio das informações disponíveis na embalagem do leite em pó foi possível calcular a concentração de proteína inicial e então determinar a rejeição da membrana à proteina através da Equação 3. Os dados disponíveis na embalagem do leite em pó assim como a concentração e rejeição calculadas são apresentados na Tabela 1.

$$
\text { Rejeição }(\%)=\left(1-C_{p} / C_{a}\right) 100
$$

Onde $C_{p}$ é a concentração de permeado (solução dialisante) e $C_{a}$ é a concentração da alimentação.

Tabela 1- Concentrações inicial e média de proteína na solução dialisante e rejeição da proteína à membrana.

\begin{tabular}{c|c|c|c}
\hline $\begin{array}{c}\text { Porcentagem de } \\
\text { proteínas no leite em } \\
\text { pó (\%) }\end{array}$ & $\begin{array}{c}\text { Concentração de } \\
\text { proteínas na } \\
\text { alimentação }\left(\mathrm{mg} \cdot \mathrm{mL}^{-1}\right)\end{array}$ & $\begin{array}{c}\text { Concentração média de } \\
\text { proteínas na solução } \\
\text { dialisante }\left(\mathrm{mg} \cdot \mathrm{mL}^{-1}\right)\end{array}$ & $\begin{array}{c}\text { Rejeição } \\
(\%)\end{array}$ \\
\hline 25,8 & 2,58 & 0,0049 & 99,8 \\
\hline
\end{tabular}

Santos (2014) na avaliação de membranas de poli(éter imida) para hemodiálise reportou valores de rejeição de albumina de $99,0 \%$. Neste trabalho, obteve-se uma rejeição de $99,8 \%$, o que demonstra a capacidade desse sistema em reter e concentrar proteínas. No entanto, é notável a limitação que esse processo oferece para a indústria: dificuldade de escalonamento e necessidade de quantidade apreciável de solvente para a solução externa; nesse processo a diluição foi de 100 vezes. É um processo que possibilita concentrar eficientemente, mas em pequena escala, sendo portanto, justificado seu uso principalmente quando o objetivo é separar produtos de alto valor agregado. Além disso, processos de separação de proteínas usuais como o salting-out podem influenciar a estabilidade estrutural dessas moléculas, o que pode se tornar muito relevante quando essas proteínas tem atividade enzimática, e nesse caso também, o uso da diálise pode ser justificado.

Na principal aplicação da diálise, que é na hemodiálise, é importante a retenção de proteínas, como a albumina, presentes no sangue pois a perda de albumina e redução da 
permeabilidade difusiva causada pela adsorção de proteínas nas membranas dificultam a adequação da diálise aos pacientes (AOYAGI et al., 2004). É desejável que essas membranas apresentem características como biocompatibilidade e alta permeabilidade.

No caso das membranas de acetato de celulose, essa é considerada biocompatível e de alto fluxo (IDRIS e YET, 2006), mas é constituída de grupos hidroxilas que conferem hidrofilicidade à membrana. $\mathrm{Na}$ hemodiálise, quando essas membranas puramente de celulose entram em contato com o sangue é observado um aumento da ativação do complemento e leucopenia, o que não é desejado (NUNES, 2011). Por isso, o que se tem feito é a produção de membranas de celulose modificadas, com a substituição dos grupos hidroxil por outros grupos, como grupos acetil, por exemplo, ou ainda a substituição de uma pequena percentagem dos radicais hidroxil por um grupo químico volumoso, que também diminui a ativação do complemento da membrana (BERTONCELLO, 2007).

De fato, a modificação de membranas é uma realidade atual e para o contínuo avanço desses processos de separação, muitos estudos tem sido conduzidos para desenvolver novos materiais, otimizar os processos de preparo das membranas e entender os mecanismos de transporte através delas (SHI et al., 2017).

\section{CONCLUSÃO}

Esse trabalho apresentou um experimento simples e didático para a compreensão por estudantes de engenharia e áreas correlacionadas, do funcionamento de uma membrana de diálise na separação de dois componentes com aplicações conhecidas: concentração de proteínas e separação de sais. Com esse experimento, é possível avaliar a transferência de massa através da membrana através do monitoramento da concentração dos componentes envolvidos com o tempo, além de avaliar a eficiência de separação da membrana por meio do cálculo da \% de rejeição da membrana à proteína. $\mathrm{O}$ experimento se mostra adequado como prática laboratorial de ensino pelo rápido alcance do equilíbrio e pelo tempo de execução.

\section{REFERÊNCIAS}

AOYAGI, S.; HAYAMA, M.; HASEGAWA, U.; SAKAI, K.; HOSHI, T.; KUDO, M. TOFSIMS imaging of protein adsorption on dialysis membrane. Applied surface science, Japan, 232(2004) 411415.

ARMOA, M.H.;JAFELICCI JR., M. Princípios e aplicações de processos de separação por membranas inorgânicas. Ciência \& Tecnologia: Fatec-Jb, Jaboticabal, v.2, n.1, p.80-97, 2011.

BERTONCELLO, I. Influência do tipo de membrana de hemodiálise e da sua reutilização nos marcadores de estresse oxidativo. 2007. 67f. Dissertação (Mestrado em Bioquímica Toxicológica)- Universidade Federal de Santa Maria, Santa Maria, 2007.

BRASIL, R.B. Estrutura e estabilidade das micelas de caseína do leite bovino. Seminários aplicados do programa de pós-graduação em Ciência Animal da escola de veterinária e Zootecnia da Universidade Federal de Goiás, Goiás, 2013.

CASTRO, M.D.L.; CAPOTE, F.P.; ÁVILA, N.S. Is dialysis alive as a membrane-based separation technique? Trends in Analytical Chemistry, v.27, n.4, 2008. 
HABERT, A.C.;BORGES, C.P.; NOBREGA, R. Processos de separação com membranas. Rio de Janeiro: E-papers, 2006.

HELLER, L.; PÁDUA, V.L. Abastecimento de água para consumo humano. Belo Horizonte: Editora UFMG.

IDRIS, A.; YET, L.K. The effect of different molecular weight PEG additives on cellulose acetate asymmetric dialysis membrane performance. Journal of Membrane Science, Malaysia 280 (2006) 920-927.

LIN, X.; S, E.; KONG, B.;LIU, J.Z.;HU, Y.;XU, T.;WANG, H. Porous diffusion dialysis membranes for rapid acid recovery. Journal of Membrane Science, 502(2016) 76-83.

LUO, J.; WU, C.; XU, T.; WU, Diffusion dialysis-concept, principle and applications. Journal of Membrane Science, China, 366 (2011) 1-16.

MORAES, C.S.; OLIVEIRA, F. O.R.; MASSON, G.; SANTOS, L.O.; BASTOS, N.F. P; FARIA, R.C.R. Métodos Experimentais no estudo de proteínas. Rio de Janeiro: IOC, 2013.

MULDER, M. Basic principles of membrane technology. Kluwer Academic Publishers, 1996.

NUNES, N.D.P. Aplicação das membranas na área médica- Órgãos artificiais. 2011. 39f. Trabalho de diplomação em Engenharia Química- Universidade Federal do Rio Grande do Sul, Porto Alegre, 2011.

SALGIN, S.; TAKAÇ, S.; ÖZDAMAR, T. H. Adsorption of bovine serum albumin on polyether sulfone ultrafiltration membranes: Determination of interfacial energy and effective diffusion coefficient. Journal of Membrane Science, Turquey, 278 (2006) 251-260.

SANTOS, A.M. Desenvolvimento de membranas de poli(éter imida) funcionalizadas para aplicação em hemodiálise. 2014. 127f. Dissertação (Mestrado em Engenharia Química)- Instituto Alberto Luiz Coimbra, Rio de Janeiro, 2014.

SHI, B.; MARCHETTI, P.; PESHEV, D.; ZHANG, S.; LIVINGSTON, A.G. Will ultra-high permeance membranes lead to ultra-efficient processes? Challenges for molecular separation in liquid systems. Journal of Membrane Science. 525 (2017) 35-47.

TRINDADE, E.A. Proteínas. Rev. Food Ingredients Brasil, n. 28, 2014. Disponível em < http://revista-fi.com.br/upload_arquivos/201606/2016060879641001464957906.pdf $>$ Acesso em 29 de Agosto de 2017.

XU, C.; XUE, S.; WANG, P.; WU, C. WU, Y. Diffusion dialysis for $\mathrm{NaCl}$ and $\mathrm{NaAc}$ recovery using polyelectrolyte complexes/ PVA membranes. Separation and Purification Technology, China, 172 (2017) 140-146.

YEH, H.; HSU, C. Analysis of dialysis coupled with ultrafiltration through concurrently parallel-flow rectangular membrane modules. Chemical Engineering and Processing: Process Intensification, Taiwan, 69 (2013) 90-94. 